\title{
The effectiveness of Sandplay Therapy in children who are victims of maltreatment with internalizing and externalizing behavior problems
}

\author{
A efetividade da Terapia do Sandplay em crianças vítimas \\ de maus tratos com problemas de comportamento \\ internalizantes e externalizantes
}

Reinalda Melo da MATTA ${ }^{1}$ (D) 0000-0001-7933-4430
Denise Gimenez RAMOS ${ }^{1}$ (D) 0000-0002-1639-5102

\begin{abstract}
This study aims to investigate the effect of Sandplay Therapy on the treatment of children who are victims of mistreatment with internalizing and/or externalizing behavioral problems. Method: The Child Behavior Check List instrument was applied to all children between 6 years 6 months and 10 years 11 months from 24 institutions. All of them presented clinical and/or borderline levels of behavior concern. The institutions where the children would compose a control group, those where they would receive Sandplay Therapy treatment (experimental group), and those where they would receive Placebo treatment were determined by drawing lot. The same instrument was applied after the treatments, or 20 weeks; in the experimental group, a test was applied after six months. The results show that the children in the experimental group showed significant improvements. These changes remained six months after the end of therapy and were verified by analyzing Sandplay scenarios.
\end{abstract}

Keywords: Brief psychotherapy; Child abuse; Child behavior disorder; Child psychotherapy; Sheltered children.

\section{Resumo}

O presente estudo tem como objetivo investigar o efeito da Terapia do Sandplay no tratamento de crianças vítimas de maus tratos e com problemas de comportamento internalizantes e/ou externalizantes. Participantes: 60 crianças vítimas

\footnotetext{
$\boldsymbol{\nabla} \nabla \boldsymbol{\nabla}$
}

1 Pontifícia Universidade Católica de São Paulo, Programa de Pós-Graduação em Psicologia Clínica. R. Monte Alegre, 696, Perdizes, 05014-001, São Paulo, SP, Brasil. Correspondence to: R.M. MATTA. E-mail: <reinalda53@gmail.com>.

Support: Coordenação de Aperfeiçoamento de Pessoal de Nivel Superior (Process no 29730).

Article based on the dissertation of R.M. MATTA, entitled "Trauma em crianças em acolhimento institucional: avaliação e transformação por meio do processo psicoterapêutico da terapia do Sandplay”. Pontifícia Universidade Católica de São Paulo, 2015.

How to cite this article

Matta, R. M., \& Ramos, D. R. (2021). The effectiveness of Sandplay therapy in children who are victims of maltreatment with internalizing and externalizing behavior problems. Estudos de Psicologia (Campinas), 38, e200036. https://doi.org/10.1590/1982$0275202138 \mathrm{e} 200036$ 
de maus tratos e institucionalizadas. O instrumento Child Behavior Checklist foi aplicado nas crianças avaliadas, todas com idades entre 6 anos e 6 meses e 10 anos e 11 meses, de 24 instituições. Todas apresentaram níveis clínicos elou limitrofes. Por sorteio, foi determinado em qual instituição as crianças seriam grupo controle e em quais receberiam tratamento com terapia de Sandplay (grupo experimental) ou tratamento placebo. O mesmo instrumento foi aplicado após tratamentos ou 20 semanas; no grupo experimental houve testagem após seis meses. Os resultados demonstram que as crianças do grupo experimental apresentaram melhoras significativas. Essas mudanças ainda eram perceptíveis seis meses após o término da terapia e foram verificadas pela análise dos cenários de Sandplay

Palavras-chave: Psicoterapia breve; Abuso da criança; Transtorno de comportamento infantil; Psicoterapia da criança; Crianças abrigadas.

Numerous studies show that children who are victims of abuse (which includes being neglected, abandoned, physically and / or psychologically abused) can have serious short and long-term impairments in cognitive, socio-emotional, and behavioral processes (Hecker, Boettcher, Landolt, \& Hermenau, 2019; Hovens, Giltay, van Hemert, \& Penninx, 2015; Kirke-Smith, Henry, \& Messer, 2015; Lewis, McElroy, Halaar, \& Runyan, 2016; McLaughlin \& Sheridan, 2016; Muniz et al., 2019; Parlar et al., 2014).

In Brazil, studies on the topic are extremely important since, according to the Centro de Combate à Violência Infantil (Center for Combating Child Violence), 12\% of the 55,6 million children under the age of 14 are victims of some form of domestic violence every year. These data reveal that about 18 thousand children suffer violence every day, 750 every hour, and 12 every minute (Centro de Combate à Violência Infantil, 2009).

About domestic violence, we can have different types of abuse: physical, psychological, and sexual, risky behaviors for the perpetration of aggressive behaviors and difficulties in social interactions in adolescence (Sowel, Leon, \& Van Liew, 2019). Vasileva and Petermann (2018), in their review of the literature on children living in shelters due to domestic violence conclude that they had patterns of developmental problems and psychopathologies that may be related to a context of multiple risk behaviors. The main developmental problems highlighted in this literature review are linked to attachment disorder, depression, and behavioral problems.

Countless authors, based on empirical observations derived from research and from psychoanalytic, psychotherapeutic and psychiatric environments, report that physical, sexual, and emotional or psychological abuse and neglect are associated with a diverse spectrum of psychiatric consequences both in childhood and in adulthood, including internalizing and externalizing behavior problems according to the Child Behavior Check List (CBCL) (Infurna, Reich, Schimmenti, Bifulco, \& Kaess, 2016; Rosen, Handley, Cicchetti, \& Rogosch, 2018; Vahl, van Damme, Doreleijers, Vermeiren, \& Colins, 2016).

Children who suffer physical and/or psychological domestic violence have a higher risk of depression in adolescence and adulthood, partially mirroring the family context in which this violence occurred. While physical abuse can trigger more externalizing behavior problems, neglect can lead to more internalizing behavior problems (Augusti, Baugerud, Sulutvedt, \& Melinder, 2018; D'Andrea, Ford, Stolbach, Spinazzola, \& van Der Kolk, 2012; Helton, Gochez-Kerr, \& Gruber, 2017). In a sample from a school in the city of Porto Alegre (Brazil), a high prevalence of internalizing and aggressive behavior problems was found in elementary school children (Callegaro \& Tiellet, 2011).

Some studies also reveal that children who experience multiple types of abuse show high levels of externalizing behavior, emotional dysregulation, depression, and anxiety (Warmingham, Handly, Rogosch, Manly, \& Cicchetti, 2019).

As we can see, the $\mathrm{CBCL}$ instrument has been extensively used in numerous studies as it is a standardized international measure of high quality that aims to assess emotional, behavioral, and social skills in children. It consists of the following scales: internalizing behavior problems (withdrawal, somatic complaints, depression /

2 anxiety) and externalizing behavior problems (aggressive and rule-breaking behavior) (Achenbach, 2001). 
The association between traumatic events in childhood, anxiety, comorbidities, and depressive disorders contributes to the severity of psychiatric disorders in adolescence and adulthood, related to a context of multiple risk behaviors, especially persistent physical and psychological abuse (Hovens et al., 2015; Mello et al., 2009; Read, Harper, Tucker, \& Kennedy, 2018). These findings increase the need for interventions, focusing not only on the symptom itself, but on reducing complex consequences in adults (Hodges et al., 2013; Zeanah \& Humphreys, 2018). Likewise, Mello et al. (2009), Silva, Azambuja, and Santana (2015) note that these children have a higher risk of victimization in interpersonal relationships and a greater likelihood of emotional maladjustments in adulthood, revealing that about a quarter or a third of the abused children have major depression when they are in their late 20 s.

Corroborating these data, Schore $(2003,2007)$ and Cecil, Essi, Pasco, Glaser, and McCrory (2017) state that abuse and violence not only expose an immature child to threatening experiences, but also impede the development of the brain/ mind/ body regarding interpersonal experiences that facilitate growth, which are necessary for brain maturation.

With these studies, the importance of early and preventive psychotherapeutic measures is reinforced before victims fall into chronic patterns of disorganization and destructiveness against themselves and others. The choice of treatment should be discussed in societies, in order to provide active assistance to children and their families. However, the development of effective interventions for victims to acquire skills to deal with uncomfortable emotional and physical sensations and to be able to process their traumatic experiences is still a challenge (Toth \& Manly, 2019; van Der Kolk, Roth, Pelcovitz, Sunday, \& Spinazzola, 2005; van Westrhenen, Fritz, Vermeer, Boelen, \& Kleber, 2019).

Among the techniques developed, Howe (2005) points out that sensory integration helps children to feel calm and relaxed and to recognize, control and distinguish different sensations, suggesting the use of non-verbal techniques, among them, Sandplay Therapy (ST). It is a non-verbal and creative therapy, based on the analytical theory of Carl Gustav Jung, in which the subjects create scenes or drawings with their hands, using boxes of dry or wet sand, water, miniatures, scraps, and objects of nature. This treatment offers the opportunity for unconscious traumatic components, often kept under control by mechanisms of defense, may appear and be symbolically revealed in the scenarios, expressing needs and emotions (Friedman \& Mitchell, 1994; Kalff, 2003; Roesler, 2019). Several clinical cases and ST studies with children, adolescents, and adults who are victims of abuse show that the symbolization of situations of conflict and suffering, through the spontaneous construction of scenarios and related stories, allows the integration of psychic contents and the externalization of aggressive and destructive trends, converting the core of defensive structures into creative ones, so that the ego can be gradually modified and strengthened (Adams, 2007; Balfour, 2008; Doyle \& Margor-Blatch, 2017; Herrmann, 2008, 2011; Hong, 2011; Kalff, 2003). A recent study, carried out with children sheltered in the Republic of Korea, also presented effective results in reducing externalizing behavior problems when undergoing ST in the form of brief therapy (Youjin, Yuseon, \& Joo, 2017).

In this review, regarding the Brazilian context, no studies were found using a non-verbal technique with children who were victims of abuse. In view of these findings, the present study aims to investigate the effect of Sandplay Therapy in the treatment of children who were victims of abuse with internalizing and/or externalizing behavior problems.

\section{Method}

\section{Participants}

This study was authorized by the multidisciplinary team of the Special Protection Services of the Municipality of São Paulo and the Municipal Social and Development Services, and by the coordinators of the Coordination of Social Assistance - Family Support: a total of 24 institutions gave their authorization. 
Children between six years six months and ten years old who lived in shelter institutions in the city of São Paulo, with borderline and/or clinical results in the scores of internalizing and/or externalizing behavior problems in the Cognitive Behavior Check List (CBCL)/6-18 instrument. As a general rule, the history of all institutionalized children was under secrecy. Therefore, it was not possible to access their history.

Among the 24 institutions, there were 86 children within the age range of the inclusion criterion. All were assessed and presented borderline and/or clinical results in the scores of internalizing and/or externalizing behavior problems, therefore they were included in the study.

The sample calculation was performed by the difference of interest in the means among the groups. The 7 point-score was considered as the value of interest between the difference in the CBCL/6-18 scores between the groups, and the standard deviation of 8 . We considered a type 1 error of $5 \%$, and the power of the statistical test was $80 \%$. With this, a minimum number of 20 people per group was met.

Sixty children participated in the study (20 in each group); 26 children quit the survey because they returned to their families or because they were adopted; 34 boys and 26 girls remained in the survey. The institutions were randomly selected and assigned to a type of procedure: Experimental Group (EG), Placebo Group (PG), and Control Group (CG), in order to prevent children from the PG and CG not feeling hampered for not participating in ST sessions.

The board of each institution determined two professionals who had more than one year of contact with the child to answer the instrument. They answered this instrument in the three moments of the study.

\section{Instruments}

Identification form: Age, sex, reason for reception, time of reception, and the CBCL/6-18. The CBCL/6-18 is part of the Achenbach System of Empirically Based Assessment Inventories and developed by Achenbach in 1991. It was validated in Brazil by Rocha, Pereira, Arantes, and Silvares (2010). The purpose of this inventory is to assess a child's skills and behavioral problems, according to the report of parents or educators. The Internalization Scale is the sum of the scores of the problems included in the Anxiety/Depression and Withdrawal/Depression syndromes, and Somatic Complaints. The Outsourcing Scale is the sum of the problems included in the Rule-Breaking and Aggressive Behavior syndromes. For each scale, a T 70 score represents the $98^{\text {th }}$ percentile of the normative sample. Scores equal to or greater than 70 are in the clinical range. T scores ranging from 65 (93 $3^{\text {rd }}$ percentile) to 69 ( $97^{\text {th }}$ percentile) are in the borderline range. Scores below 65 are in the normal range. The results of the instrument were assessed using the Achenbach System of Empirically Based Assessment Software

Group composition - the average age was: 8.6 years in the EG; 8.3 years in the CG and 8.0 in the PG. Regarding sex, the total distribution was: boys (41.7\%); girls (58.3\%); in EG (35.0\% males); CG (65.0\% males) and PG (25.0\% males). The time these kids spent in the institution varied between 13.2 months and 23.2 months: for the EG, 23.8 months, for the CG, 13.2 months, and for the PG 20.6 months, with no significant difference between groups in terms of age, sex, and length in shelter placement.

Sandplay Therapy technical material: two boxes with wet and dry sand (size $72 \times 50 \times 7.5 \mathrm{~cm}$ ), miniatures representing human beings, plants, mineral, and animals; buildings, means of transport, and mythical figures, and a camera. All standard technical material was used and maintained throughout the sessions.

Technical material for placebo therapy: box with dry sand (size: $40 \mathrm{~cm} \times 30 \mathrm{~cm} \times 5 \mathrm{~cm}$ ) with a $2 \mathrm{~cm}$ layer of sand; six white stones, and a rake. This material was chosen due to its similarity to the sandplay material (box with sand and the possibility of playing with it). 


\section{Procedures}

An Informed Consent Form was signed with the heads of the shelter institutions where the children lived and an Assent Form with the participating children. After that, initial assessments were performed using the CBCL/6-18 (TO). The instrument was reapplied after the end of 20 sessions for the SG and the PG, after 20 weeks for the CG (T1), and six months after T1 for the EG (T2).

Experimental Group (EG): the ST was applied in a total of 20 sessions, individually, always by the same psychologist, once a week, with an average length of 45 minutes per session. There were three professionals, all with training and experience in this technique. At the first meeting, the therapist said to the child: "You have here several miniatures and two boxes with sand: one with dry sand and the other with wet sand. You can play with these objects that are in this room. I would like you to make a scenario using the miniatures you want. After you finish and leave the room, I will take a picture of what you did". Upon completion, the child was also asked to make up a story about the setting. The therapist noted the child's verbal expressions and welcomed his or her feelings and verbalizations. The session ended when the child communicated that he or she had finished and wanted to leave. After the child left, the therapist took a picture of the scenario.

Placebo Group (PG): the PG procedure was performed by six research assistants, in 20 individual sessions, once a week, with an average length of 45 minutes. A box with sand was presented to each child with the following instructions: "You can play with this material you have here: a box with sand, a rake, and some stones". At that moment, the child could or could not verbalize his or her feelings. The meeting ended when the child said it was over and he or she wanted to leave. If the child wanted to interrupt the procedure early, the research assistant encouraged to continue playing. The aim of this group was to try to counter an occasional transference between therapist and patient, so that this would not be the only one responsible for the possible change.

Control Group (CG): the participants were on a waiting list for 20 weeks and then assessed using the CBCL/6-18 (T1) instrument. After this assessment, if they continued with the same results, they would become part of the $E G$.

This study was authorized by the Research Ethics Committee of the Pontifícia Universidade Católica de São Paulo (Pontifical Catholic University of São Paulo): Coordenação de Aperfeiçoamento de Pessoal de Nivel Superior (Coordination for the Improvement of Higher Education Personnel) opinion $n^{\circ} 29730$. Certificado de Apresentação para Apreciação Ética (Presentation Certificate for Ethical Appreciation): protocol $n^{\circ}$ 01873412.8.0000.5482. Children in the Placebo and Experimental groups after T1 (second assessment) who continued with clinical symptoms were referred to a specialized clinic.

\section{Data Analysis}

A study of the differences between groups was made for the four measurements at T0 and later it was verified whether score distribution was normal. The Shapiro Wilk test was performed, appropriate to smaller samples. All variables showed no rejection of the null hypothesis of normality, that is, they were normal. For this reason, parametric statistics were used, in this case, ANOVA.

The picture of each scenario was assessed by three collaborators, therapists trained in the ST technique. Upon reaching a consensus, one or more themes were assigned to the scenario. The analysis and organization of the scenarios in two categories of themes were carried out using the method developed by Ramos and Matta (2008): 
Category $A$ - negative themes of suffering and conflict: threat/conflict; chaos/destruction; rage; wounded or neglected. Sessions 1 to 10 (A1), sessions 11 to 20 (A2).

Category B - positive themes related to transformation and the possibility of psychological improvement: celebration, centralization, integration, path, nutrition, protection/care, and transfer. Sessions 1 to 10 (B1) and sessions 11 to 20 (B2).

\section{Results}

\section{Comparison between $\mathrm{CBCL} T 0$ results and the three group}

There was no significant difference between the three groups in the CBCL/6-18 results, both in relation to internalizing and externalizing behavior problems before the intervention: all presented borderline and/or clinical results. Internalizing behavior problems: $E G=62.7 ; C G=62.6 ; P G=65.2 ; p=0.237$. Externalizing behavior problems: $E G=70.0 ; C G=68.8 ; P G=71.7 ; p=0.340$ (Kruskal Wallis was used to test to check the differences between groups in the CBCL/6-18 results) (Table1).

Table 1

Test to check differences between the groups before and after the intervention Cognitive Behavior Therapy

\begin{tabular}{|c|c|c|c|c|c|c|c|c|c|}
\hline \multirow{2}{*}{ Group } & \multirow{2}{*}{ Behaviors } & \multicolumn{2}{|c|}{ TO } & \multicolumn{2}{|c|}{$\mathrm{T} 1$} & \multirow{2}{*}{ Z-score } & \multirow{2}{*}{$p$-value ${ }^{1}$} & \multirow{2}{*}{ Effect size (r) } & \multirow{2}{*}{ Cl 95\% } \\
\hline & & $M$ & $S D$ & $M$ & $S D$ & & & & \\
\hline \multirow{2}{*}{$\overline{E G}(n=20)$} & IBP & 62.7 & 6.30 & 52.1 & 7.08 & -3.585 & $<0.001^{*}$ & 0.80 & $0.56-0.92$ \\
\hline & EBP & 70.0 & 6.53 & 59.2 & 7.21 & -3.824 & $<0.001^{*}$ & 0.86 & $0.67-0.95$ \\
\hline \multirow[t]{2}{*}{ CG $(n=20)$} & IBP & 62.6 & 5.70 & 62.0 & 6.16 & -1.447 & 0.148 & - & - \\
\hline & EBP & 68.8 & 5.35 & 65.5 & 6.96 & -2.536 & $0.011^{*}$ & 0.57 & $0.17-0.81$ \\
\hline \multirow[t]{2}{*}{ PG $(n=20)$} & IBP & 65.2 & 4.73 & 64.3 & 5.26 & -1.047 & 0.295 & - & - \\
\hline & EBP & 71.5 & 5.28 & 70.2 & 7.28 & -1.027 & 0.304 & - & - \\
\hline
\end{tabular}

Note: * Significance level $p<0.05$; ${ }^{1}$ Wilcoxon paired test. CG: Control Group; Cl: Confidence Interval; EBP: Externalizing Behavior Problems; EG: Experimental Group; IBP: Internalizing Behavior Problems; PG: Placebo Group; TO: Before the intervention; T1: After intervention; M: Mean; SD: Standard Deviation.

There was no change in the PG. There was a significant difference in EG in all behavior problems, with a large effect size. The significant difference in the externalizing behavior problems of the CG had a medium effect size. Due to this improvement, the following externalizing behavior problems were computed separately: aggressiveness and breaking rules (Achenbach \& Rescorla, 2001) (Table 2).

Table 2

Test to check for differences in externalizing behavior problems between groups before and after the intervention

\begin{tabular}{|c|c|c|c|c|c|c|c|c|c|}
\hline \multirow{2}{*}{ Group } & \multirow{2}{*}{ Behaviors } & \multicolumn{2}{|c|}{ TO } & \multicolumn{2}{|c|}{$\mathrm{T} 1$} & \multirow{2}{*}{ Z-score } & \multirow{2}{*}{$p$-value ${ }^{1}$} & \multirow{2}{*}{ Effect size (r) } & \multirow{2}{*}{ Cl 95\% } \\
\hline & & $M$ & $S D$ & $M$ & $S D$ & & & & \\
\hline \multirow[t]{2}{*}{$\mathrm{EG}(n=20)$} & Rule-breaking & 66.1 & 6.56 & 58.2 & 6.84 & -3.933 & $<0.001^{*}$ & 0.88 & $0.72-0.96$ \\
\hline & Aggressive & 69.2 & 8.79 & 60.7 & 5.98 & -3.686 & $<0.001^{*}$ & 0.82 & $0.61-0.93$ \\
\hline \multirow[t]{2}{*}{ CG $(n=20)$} & Rule-breaking & 66.1 & 5.21 & 64.9 & 6.24 & -1.180 & 0.238 & - & - \\
\hline & Aggressive & 71.3 & 6.98 & 67.9 & 6.64 & -2.437 & $0.015^{*}$ & 0.54 & $0.14-0.80$ \\
\hline \multirow[t]{2}{*}{$\mathrm{PG}(n=20)$} & Rule-breaking & 70.4 & 4.16 & 70.2 & 7.28 & -0.166 & 0.868 & - & - \\
\hline & Aggressive & 73.8 & 7.11 & 71.9 & 6.53 & -1.506 & 0.132 & - & - \\
\hline
\end{tabular}

Note. "Significance level $p<0.05 ;{ }^{1}$ Wilcoxon paired test. CG: Control Group; Cl: Confidence Interval; EG: Experimental Group; PG: Placebo Group; TO: 
In the EG, we can see a reduction in both aggressive behavior and in rule-breaking behavior (both with large effect size); in the CG, the reduction was only in aggressive behavior, with a medium effect size.

Only 12 children participated the assessment performed six months after the intervention, as several children from the three groups were referred for psychological treatment, returned to their families, or adopted (Table 3).

With regard to $C B C L / 6-18$, we observed that, while the results of internalizing behavior problems remained stable in $\mathrm{T} 2$, the improvement obtained with externalizing behavior problems in $\mathrm{T} 1$ continued to progress six months after the end of treatment.

Table 3

Friedman test for repeated measures - experimental group and Cognitive Behavior Therapy

\begin{tabular}{|c|c|c|c|c|c|c|c|c|c|c|c|}
\hline \multirow{2}{*}{ Variable } & \multicolumn{2}{|c|}{ T0 $(n=12)$} & \multicolumn{2}{|c|}{ T1 $(n=12)$} & \multicolumn{2}{|c|}{$\mathrm{T} 2(n=12)$} & \multirow{2}{*}{$\chi^{2}$} & \multirow{2}{*}{$\mathrm{gl}$} & \multirow{2}{*}{$p$-value ${ }^{1}$} & \multirow{2}{*}{ Effect size ${ }^{2}$} & \multirow{2}{*}{ Cl 95\% } \\
\hline & $M$ & $S D$ & $M$ & $S D$ & $M$ & $S D$ & & & & & \\
\hline IBP & 61.8 & 7.02 & 53.7 & 5.70 & 54.9 & 4.62 & 4.638 & 2 & 0.098 & - & - \\
\hline EBP & 69.4 & 5.50 & 59.3 & 6.82 & 60.2 & 9.09 & 14.340 & 2 & $0.001^{*}$ & 0.60 & $0.20-0.88$ \\
\hline
\end{tabular}

Note: "Significance level $p<0.05$; ${ }^{1}$ Wilcoxon paired test; ${ }^{2}$ Kendall's W; CG: Control Group; Cl: Confidence Interval; EBP: Externalizing Behavior Problems; IBP: Internalizing Behavior Problems; PG: Placebo Group; TO: Before the intervention; T1: After intervention; M: Mean; SD: Standard Deviation.

\section{Analysis of the scenarios}

The proportion between the number of positive and negative scenarios in relation to the total number was computed in the first and second stages of the process. Table 4 shows the evolution of the therapeutic processes of the group of participants.

We can see that there was no difference between negative (A1) and positive (B1) themes, at the beginning of the process, from sessions 1-10. Therefore, until reaching the halfway point of the treatment, the children had equivalent numbers of positive and negative scenarios. At the end of the process, there was a significant increase in positive scenarios compared to negative ones (B2 > A2), a significant decrease in negative scenarios between the first and second phases of therapy $(A 1<A 2)$ and a significantly higher proportion of positive scenarios (B2 > B1). The themes that revealed significant differences between the first and second phases were: threat/conflict, hurt/wounded, neglect, and defense (decreased); and those related to psychological transformation and improvement (increased) were: centralization and integration (Table 5).

Table 4

Test to check differences between the proportions of negative themes (A1 and A2) and positive themes (B1 and B2) of Sandplay Therapy

Negative and positive themes

Experimental group

\begin{tabular}{lll}
\hline A1 - ratio between the number of scenarios with negative themes and the total of scenarios (sessions 1 - 10) & 46.3 & 53.7 \\
B1 - ratio between the number of scenarios with positive themes and the total of scenarios (sessions 1 - 10) & 0.333 \\
\hline A2 - ratio between the number of scenarios with negative themes and the total of scenarios (sessions 11 - 20) & 35.6 & 64.4 \\
B2 - ratio between the number of scenarios with positive themes and the total of scenarios (sessions 11 - 20) & $0.001^{*}$ \\
\hline A1 - ratio between the number of scenarios with negative themes and the total of scenarios (sessions 1 - 10) & 46.3 & 35.6 \\
A2 - ratio between the number of scenarios with negative themes and the total of scenarios (sessions 11 - 20) & $0.002^{*}$ \\
\hline B1 - ratio between the number of scenarios with positive themes and the total of scenarios (sessions 1 - 10) & 53.7 & 64.4 \\
B2 - ratio between the number of scenarios with positive themes and the total of scenarios (sessions 11 - 20) & $0.002^{*}$ \\
\hline
\end{tabular}

Note: "Significance level $p<0.05 ;{ }^{1} \mathrm{~T}$ test for paired samples; A1: Themes of suffering and conflict, sessions 1-10; B1: Themes related to psychological improvement, sessions 1-10; A2: Themes of suffering and conflict, sessions 11-20; B2: Themes related to psychological improvement, sessions 11-20. 
Table 5

Test to check the differences between the mean of negative themes (A1 and A2) and positive themes (B1 and B2) of Sandplay Therapy

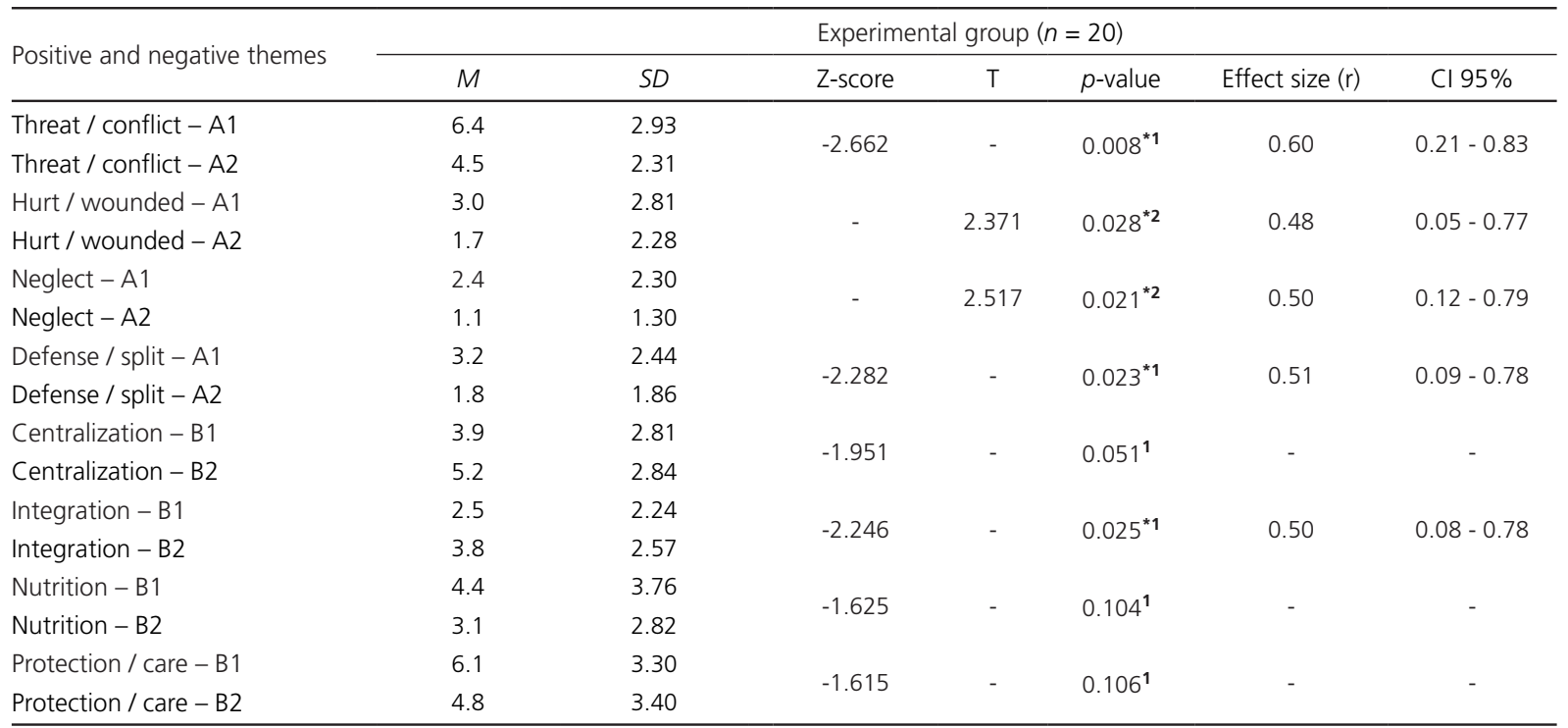

Note: " Significance level $p<0.05 ;{ }^{1} \mathrm{~T}$ test for paired samples; ${ }^{2} \mathrm{~T}$ test for paired samples; $\mathrm{A} 1$ : Themes of suffering and conflict, sessions 1 -10; $\mathrm{B} 1$ : Themes related to psychological improvement, sessions 1-10; A2: Themes of suffering and conflict, sessions 11-20; B2: Themes related to psychological improvement, sessions 11-20; T: Critical value of t-distribution $(n-1)$ degrees of freedom; M: Mean; SD: Standard Deviation.

We can observe that the negative themes, that is, those that express suffering and conflict (threat/ conflict, hurt/wounded, neglect, and defense) had a significant decrease while the scenarios related to centralization and integration increased; all with medium effect size.

\section{Discussion and Conclusion}

The present study was carried out in Shelter Institutions with children who were victims of abuse. The lack of information regarding the children's history, for legal reasons, did not allow a comparative analysis regarding the severity of their maltreatment, although we knew some had suffered serious physical abuse, including sexual abuse.

In the initial phase, the caregivers' reports showed the difficulty of these children to modulate their emotions and adapt to school and social situations. The initial results corroborate with the conclusions of Hildyard and Wolfe (2002) that neglected children can have serious short- and long-term impairments, in the socio-emotional and behavioral processes, showing a significant challenge regarding their development and well-being. In the same way as D'Andrea et al. (2012), it is considered that the variety of symptoms presented may indicate affective and behavioral dysregulation in these children. These data are congruent with the investigations carried out by several authors who discuss the symptoms related to aggressive and rule-breaking behaviors associated with the presence of intense emotions and the need for psychotherapeutic measures to prevent the continuity of pathological behaviors (Cowel, Cicchetti, Rogosch, \& Toth, 2015; D'Andrea et al., 2012; Oswald, Heil, \& Goldbeck, 2010; Viodres-Inque \& Ristum, 2008).

In view of this problem, the present study was carried out to test the effectiveness of a psychotherapeutic technique, ST, in a brief therapy format. As we have seen, the results show a significant change in internalizing and externalizing behavior problems, maintained after six months. The reduction in aggressive behaviors 8 present in the SG was also observed in the $C G$, although with a smaller effect size $(E G=0.82$ and $C G=0.54)$. 
Here, we can think about whether this result could be due to the rules of the institutions and the effect of institutionalization. Many of these children who lived on the street or in broken homes, for the first time, lived in a place that had structure and order, with rules to be followed, a place to sleep and meal times. During the intervention, very clear control rules were observed in the institutions: when the child had a "bad behavior", he or she was deprived of some privileges. It is possible that these controls may have contributed to the decrease in aggressive behaviors, although it was not possible to understand the reason for not decreasing PG levels.

In the analysis of the Sandplay images, the improvement in the thematic quality of the scenes is evident. The scenarios that represented suffering and conflicts were predominant in the first phase, congruent with the initial results in the CBCL. These scenarios, with threat/conflict, hurt/wounded, neglect, and defense/split themes, represented possible situations experienced by the participants. In this phase, scenes of violence, wars, and death were frequent, expressing feelings of anger and sadness through conflicting, wounded, and dead characters.

In the second phase of the process, negative scenarios decreased significantly while those related to psychological transformation and improvement increased (centralization and integration). These results indicate that there was a change in behavior and control over impulsive acts, also observed in the reduction of externalizing and internalizing behavior problems. With the elaboration of the scenarios and the stories told by the children and the possibility of playing in a free and protected space, it was effective in reducing aggressive and depressive symptoms. These results are similar to those obtained by Youjin et al. (2017).

It is interesting to note that there was no change in the number of scenarios with the themes of nutrition and protection, which remained high throughout the process, possibly expressing the helplessness and needs of these children who have undergone numerous deprivations, including food insecurity.

In the end, the children showed greater awareness of themselves, with scenarios of greater organization, harmony, and psychic integration. With the non-interpretive participation of a qualified therapist, it was possible to express deep unconscious contents related to conflicting situations and the development of a sense of authorship: a more mature ego with greater control over impulsiveness (Knox, 2011).

In conclusion, the present study demonstrates the effectiveness of the proposed clinical treatment for sheltered children who were victims of maltreatment, with internalizing and externalizing behavior problems. The maintenance of results, six months after the end of the treatment, confirms this fact.

Although, unlike usual clinical practices, the results demonstrate that ST in the form of brief therapy (20 sessions) can be effective and used as a brief intervention strategy and capable of promoting changes in self-regulatory processes, in a developmental perspective.

\section{Acknowledgments}

We would like to thank Carolina de Castro Lemos, Claudia Leifert, Fernanda Sodré, lara Caldeira Amaral, Isadora Concenza, and Olivia Benazzi, who participated in the T0, T1, and T2 assessments. We would also like to thank Irene Maria Crespo and Serafina Dumbra Toloni, psychologists who assisted in the psychological care of children.

\section{Contributors}

R. M. MATTA contributed to the conception and design of the study, analysis, interpretation of data, corrections and discussion of results, as well as the revision of the final version of the article. D. G. RAMOS contributed to the conception, guidance for preparation and revision of the final version. 


\section{References}

Achenbach, T. M., \& Rescorla, L. A. (2001). Manual for the ASEBA School-age forms \& profiles. Burlington: University of Vermont.

Adams, K. (2007). Reconnecting to the source: recovering from sexual molestation. Journal of Sandplay Therapy, 16(2), 55-73.

Augusti, E. M., Baugerud, G. A., Sulutvedt, U., \& Melinder, A. (2018). Maltreatment and trauma symptoms: does type of maltreatment matter? Psychological Trauma: Theory, Research, Practice, and Policy, 10(4), 396-401. http://dx. doi. org/10.1037/tra0000315

Balfour, R. N. (2008). Evolution of sandplay images in healing: a case of childhood sexual abuse of a 36-year-old woman. Journal of Sandplay Therapy, 17(2), 33-49.

Callegaro B. J., \& Tiellet N. M. L. (2011) Prevalência de problemas de comportamento em uma amostra de crianças em idade escolar da cidade de Porto Alegre. Aletheia, 34, 32-46

Cecil, A. M., Essi, V., Pasco, F., Glaser, D., \& McCrory, J. (2017). Disentangling the mental health impact of childhood abuse and neglect. Child Abuse and Neglect, 63(1), 106-119. http://dx.doi.org/10.1016/j.chiabu.2016.11.024

Centro de Combate à Violência Infantil. (2009). Dados científicos. Violência física - Estatísticas: dados estatísticos, principais caracteristicas, perfil da vítima, perfil do agressor, etc. Curitiba: CECOVI.

Cowel, R., Cicchetti, D., Rogosch, F., \& Toth, S. (2015). Childhood maltreatment and its effect on neurocognitive functioning: timing and chronicity matter. Development and Psychopathology, 27(2), 521-533. http://dx.doi. org/10.1017/S0954579415000139

D'Andrea, W. D., Ford, J., Stolbach, B., Spinazzola, J., \& van Der Kolk, B. A. (2012). Understanding interpersonal trauma in children: why we need a developmentally appropriate trauma diagnosis. American Journal of Orthopsychiatry, 82(2), 187-200. htttp://dx.doi.org/10.1111/j.1939-0025.2012.01154.x

Doyle, K., \& Magor-Blatch, L. E. (2017). "Even adults need to play": sandplay therapy with an adult survivor of childhood abuse. International Journal of Play Therapy, 26(1), 12-22. http://dx.doi.org/10.1037/pla0000042

Friedman, H., \& Mitchell, R. (1994). Sandplay: past, present, and future. New York: Routledge.

Hecker, T., Boettcher, V. S., Landolt, M. A., \& Hermenau, K. (2019). Child neglect and its relation to emotional and behavioral problems: a cross-sectional study of primary school-aged children in Tanzania. Development and Psychopathology, 31, 325-339. http://dx.doi.org/10.1017/S0954579417001882

Helton, J. J., Gochez-Kerr, T., \& Gruber, E. (2017). Sexual abuse of children with learning disabilities. Child Maltreatment, 23(2), 157-165. http://dx.doi.org/10.1177/1077559517733814

Hermann, S. B. (2008). Treatment of an abandonment trauma. Journal of Sandplay Therapy, 17(2), 51-73.

Hermann, S. B. (2011). Transformation of violence: the case of Jacob. Journal of Sandplay Therapy, 20(1), 117-132.

Hildyard, K. L., \& Wolfe, D. A. (2002). Child neglect: developmental issues and outcomes. Child Abuse and Neglect, 26, 679-695. https://doi.org/10.1016/S0145-2134(02)00341-1

Hodges, M., Godbout, N., Briere, J., Lanktree, C., Gilbert, A., \& Kletzka, N. T. (2013). Cumulative trauma and symptom complexity in children: a path analysis. Child Abuse and Neglect, 37(11),891-898. http://dx.doi.org/10.1016/j. chiabu.2013.04.001

Hong, G. (2011). Sandplay Therapy: research and practice. New York: Routledge.

Hovens, J. G. F. M., Giltay, E. J., van Hemert, A. M., \& Penninx, B. J. H. (2015). Childhood maltreatment and the course of depressive and anxiety disorders: the contribution of personality characteristics. Depression and Anxiety, 33(1), 27-34. http://dx.doi.org/10.1002/da.22429

Howe, D. (2005). Child abuse and neglect: attachment, development and intervention. London: Palgrave MacMillan.

Infurna, M. R., Reich, C., Schimmenti, A., Bifulco, A., \& Kaess, M. (2016). Associations between depression and specific childhood experiences of abuse and neglect: a meta-analysis. Journal of Affective Disorders, 190(15), 47-55. http:// dx.doi.org/10.1016/j.jad

Kalff, D. M. (2003). Sandplay: a psychotherapeutic approach to the psyche? Santa Monica: Sigo Press.

Kirke-Smith, M., Henry, L. A., \& Messer, D. (2015). The effect of maltreatment type on adolescent executive functioning and inner speech. Infant and Child Development, 25(6), 516-532. http://dx.doi.org/10.1002/icd 
Knox, J. (2011). Self-agency in psychotherapy (attachment, autonomy and intimacy). London: Routledge.

Lewis, T., McElroy, E., Harlaar, N., \& Runyan, D. (2016). Does the impact of child sexual abuse differ from maltreated but non-sexually abused children? A prospective examination of the impact of child sexual abuse on internalizing and externalizing behavior problems. Child Abuse and Neglect, 1, 31-40. http://dx.doi.org/10.1016/j.chiabu016

McLaughlin, K. A., \& Sheridan, M. A. (2016). Beyond cumulative risk: a dimensional approach to childhood adversity. Current Directions in Psychological Science, 25(4), 239-245. http://dx.doi.org/10.1177/0963721416655883

Mello, M. F., Faria, A. A., Mello, A. F., Carpenter, L. L., Tyrka, A., \& Price, L. H. (2009) Maus-tratos na infância e psicopatologia no adulto: caminhos para a disfunção do eixo hipotálamo-pituitária-adrenal. Revista Brasileira de Psiquiatria, 31(2), 41-48. http://dx.doi.org/10.1590/S1516-44462009000600002

Muniz, C. N., Fox, B., Miley, L. N., Delisi, M., Cigarran, G. P., \& Birnbaum, A. (2019). The effects of adverse childhood experiences on internalizing versus externalizing outcomes. Criminal Justice and Behavior, 46(4), 568-589. http:// dx.doi.org/10.1177/0093854819826213

Oswald, S. H., Heil, K., \& Goldbeck, L. (2010). History of maltreatment and mental health problems in foster children: a review of literature. Journal of Pediatric Psychology, 35(5), 462-472. https://doi.org/10.1093/jpepsy/jsp114

Parlar, M., Frewen, P., Nazarov, A., Oremus, C., MacQueen, G., Lanius, R., \& McKinnon, M. C. (2014). Alterations in empathic responding among women with posttraumatic stress disorder associated with childhood. Brain and Behavior, 4(3), 381-389. http://dx.doi.org/10.1002/brb3.215

Ramos, D. G., \& Matta, R. M. (2008). Sandplay: a method for data analysis. Journal of Sandplay Therapy, 17(2), 93-115.

Read, J., Harper, D., Tucker, I., \& Kennedy, A. (2018). Do adult mental health services identify child abuse and neglect? A systematic review. International Journal of Mental Health Nursing, 27, 7-19. http://dx.doi.org/10.1111/inm.12369

Rocha, M. M., Pereira, R. F., Arantes, M. C., \& Silvares, E. F. M. (2010). Guia para profissionais da saúde mental sobre o Sistema Achenbach de Avaliação Empiricamente Baseada (ASEBA). São Paulo: Universidade de São Paulo.

Roesler, C. (2019). Sandplay therapy: an overview of theory, applications and evidence base. The arts in Psychotherapy, 64, 84-94. http://dx.doi.org/10.1016/j.aip.2019.04.001

Rosen, A. L., Handley, E. D., Cicchetti, D., \& Rogosch, F. A. (2018). The impact of patterns of trauma exposure among low-income children with and without histories of child maltreatment. Child Abuse and Neglect, 80, 301-311. http:// dx.doi.org/10.1016/j.chiabu.2018.04.005

Schore, A. N. (2003). Affect regulation and the repair of the self. New York: W.W. Norton \& Company.

Schore, A. N. (2007) Psychoanalytic research, progress, and process: developmental affective neuroscience and clinical practice. Psychologist-Psychoanalyst, 27(3), 6-15.

Silva, R. W. S., Azambuja, C. V., \& Santana, A. (2015) Perfil de crianças e adolescentes vítimas de maus-tratos atendidos em ambulatório de psicologia da região sul do Brasil. Aletheia, 47, 136-141.

Sowell, M., Leon G., \& van Liew, C. (2019). The effects of stage of onset and type of abuse on cooperation and aggression in children. Journal of Articles in Support of the Null Hypothesis, 16(1), 1-10.

Toth, S. L., \& Manly, J. T. (2019) Developmental consequences of child abuse and neglect: implications for intervention. Child Development Perspectives, 13(1), 59-64. http://dx.doi.org/10.1111/cdep.12317

Vahl, P., van Damme, L., Doreleijers, T., Vermeiren, R., \& Colins, O. (2016). The unique relation of childhood emotional maltreatment with mental health problems among detained male and female adolescents. Child Abuse and Neglect, 62, 142-150. http://dx.doi.org/10.1016/j.chiabu.2016.10.008

van Der Kolk, B. A., Roth, S., Pelcovitz, D., Sunday, S., \& Spinazzola, J. (2005). Disorders of extreme stress: the empirical foundation of a complex adaptation to trauma. Journal of Traumatic Stress, 18, 389-399. http://dx.doi.org/10.1002/ jts. 20047

van Westrhenen, N., Fritz, E., Vermeer, A., Boelen, P., \& Kleber, R. (2019). Creative arts in psychotherapy for traumatized children in South Africa: an evaluation study. Plos One, 14(2), e0210857. http://dx.doi.org/10.1371/journal. pone.0210857

Vasileva, M., \& Petermann, F. (2018). Attachment, development, and mental health in abused and neglected preschool children in foster care: a meta-analysis. Trauma, Violence and Abuse, 19(4), 443-458. http://dx.doi. org/10.1177/1524838016669503

Viodres-Inque, S. R., \& Ristum, M. (2008). Violência sexual: caracterização e análise de casos revelados na escola. Estudos de Psicologia (Campinas), 25(1), 11-21. http://dx.doi.org/10.1590/\$0103-166X2008000100002 
Warmingham, J. M., Handley, E. D., Rogosch, F. A., Manly, J. T., \& Cicchetti, D. (2019). Identifying maltreatment subgroups with patterns of maltreatment subtype and chronicity: a latent class analysis approach. Child Abuse and Neglect, 87(1), 28-39. http://dx.doi.org/10.1016/j.chiabu.2018.08.013

Youjin, H., Yuseon, L., \& Joo, H. S. (2017). Effects of a sandplay therapy program at a childcare center on children with externalizing behavioral problems. Arts in Psychotherapy, 52, 24-31. https://doi.org/10.1016/j.aip.2016.09.008

Zeanah, C. H., \& Humphreys, K. L. (2018). Child abuse and neglect. Journal of the American Academy of Child and Adolescent Psychiatry, 57(9), 637-644. http://dx.doi.org/10.1016/j.jaac.2018.06.007

Received: March 27, 2020

Final version: September 1, 2020

Approved: October 9, 2020 